\title{
INTERthesis
}

\section{DETENÇÃO: AS RELAÇÕES DE PODER ENTRE ENCARCERADOS E CARCEREIROS A PARTIR DOS ESTUDOS DE GOFFMAN E FOUCAULT}

Johanna Gondar Hildenbrand ${ }^{1}$

Lobelia da Silva Faceira ${ }^{2}$

Sebastião Meirelles Sant'anna ${ }^{3}$

\section{Resumo:}

O artigo tem a proposta de discutir as relações de poder entre encarcerados e carcereiros nas instituições penais a partir do filme Detenção (The Experiment, 2010, EUA), de Paul Scheuring. Partimos dos conceitos "instituição total" e "forma-prisão" estabelecidos por Erving Goffman e Michel Foucault, respectivamente, a fim de refletirmos sobre a forma pela qual o poder é estabelecido e exercido entre e dentro desses dois grupos (encarcerados e carcereiros). A partir do filme buscamos observar as consequências do poder cedido pela instituição aos carcereiros, tidos aqui como uma equipe dirigente, e de que forma esse mesmo poder age no grupo dos prisioneiros levando-o progressivamente à modificação da subjetividade enquanto anulação do eu civil.

Palavras-chave: Instituição. Poder. Prisão. Cinema.

\section{APRESENTAÇÂO}

O artigo pretende discutir as relações de poder entre prisioneiros e carcereiros nas instituições penais a partir da sustentação teórica e dos conceitos de Erving Goffman e Michel Foucault, tendo como critério de definição dos autores a relevância de suas obras na análise da instituição prisão e das relações de poder. Logo, não é proposta do artigo realizar uma revisão de literatura sobre a temática prisão, mas a análise das relações de poder a partir do filme Detenção (The Experiment, 2010, EUA), de Paul Scheuring.

O filme, baseado no Experimento de aprisionamento de Stanford realizado na década de 70 nos Estados Unidos e liderado pelo doutor Philip Zimbardo, consiste em

\footnotetext{
${ }^{1}$ Mestranda do Programa de Pós Graduação em Memória Social da Universidade Federal do Estado do Rio de Janeiro, Rio de Janeiro, RJ, Brasil. Bolsista pela CAPES. E-mail: johanna gondar@hotmail.com 2 Doutora em Educaçãopela Pontifícia Universidade Católica do Rio de Janeiro. Professora da Escola de Serviço Social e do Programa de Pós Graduação em Memória Social da Universidade Federal do Estado do Rio de Janeiro, Rio de Janeiro, RJ, Brasil. E-mail: lobeliasfaceira@yahoo.com.br ${ }^{3}$ Mestrando do Programa de Pós Graduação em Memória Social da Universidade Federal do Estado do Rio de Janeiro, Rio de Janeiro, RJ, Brasil. E-mail: sebastiaothauzs@hotmail.com
}

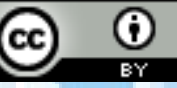
Esta obra foi licenciada com uma Licença Creative Commons Adaptada. 
um thriller ficcional sobre uma experiência comportamental promovida por uma instituição vinculada ao governo americano, no qual foram simuladas as condições de vida dentro de uma prisão estadual.

Vamos, inicialmente, apresentar um resumo do filme que funcionará como campo para nossa análise teórica: Visando receber 1.000 dólares por dia, um grupo de homens se dispõe a passar duas semanas numa "prisão fictícia" onde o único prérequisito é que não tivessem passado nenhum tempo em uma prisão real.

Após uma série de testes conduzidos para a observação da propensão individual à violência eles são encaminhados ao lugar onde fica a prisão. Lá são divididos em dois grupos: carcereiros e encarcerados, aparentemente de forma aleatória. O cientista condutor do experimento dita algumas regras apenas para os carcereiros, pois cabe a eles aplicá-las, mas essas regras devem ser seguidas por todos os participantes, caso contrário nenhum deles receberá o pagamento, visto tratar-se de uma experiência sobre grupos que são monitorados por câmeras durante todo o tempo.

As regras estabelecidas pelo grupo de pesquisadores são: 1. Os prisioneiros devem comer três refeições diárias e toda a comida do prato precisa ser consumida; 2. Os prisioneiros têm direito a trinta minutos por dia de recreação; 3. Os prisioneiros só devem estar em áreas designadas aos prisioneiros; 4. Os prisioneiros só devem falar com os guardas quando os mesmos falarem com eles; 5. Os prisioneiros não devem tocar nos guardas em nenhuma circunstância.

Qualquer um que quebre essas regras deve ser punido em no máximo trinta minutos e havendo qualquer tipo de violência física, o experimento será encerrado imediatamente e ninguém será pago. O experimento não chega a completar as duas semanas, antes disso ele é interrompido devido aos atritos que ocorrem entre o grupo de encarcerados e o grupo dos carcereiros.

No sentido de analisar o filme a partir do referencial teórico proposto, é preciso entender inicialmente o que é uma instituição penal. Foucault desenvolveu o conceito através do que ele chamou de "forma-prisão" em Vigiar e Punir (2011). No início do capítulo intitulado "Instituições Completas e Austeras" o autor nos diz que:

A forma-prisão preexiste à sua utilização sistemática nas leis penais. Ela se constitui fora do aparelho judiciário, quando se elaboram, por todo o corpo social, os processos para repartir os indivíduos, fixá-los e distribui-los espacialmente, classificá-los, tirar deles o máximo de tempo e o máximo de

R. Inter. Interdisc. INTERthesis, Florianópolis, v.11, n.2, p.55-71, Jul./Dez. 2014
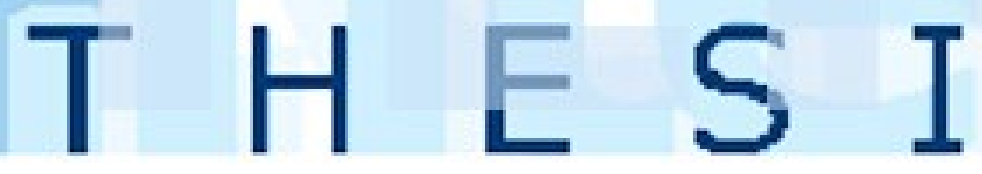
forças, treinar seus corpos, codificar seu comportamento contínuo, mantê-los numa visibilidade sem lacuna, formar em torno deles um aparelho completo de observação, registro e notações, constituir sobre eles um saber que se acumula e se centraliza. (FOUCAULT, 2011, P.217)

O indivíduo preso participa de uma organização cumprindo as obrigações, delineando padrões de bem estar, valores, incentivos e sanções, passando por processos de ajustamento a um espaço de vigilância e a um sistema de comunicação vigiado e mediado.

Goffman (1974) em sua obra Manicômios, prisões e conventos define as prisões como instituições penais, destacando sua característica de fechamento, massificação e mortificação da subjetividade do preso:

\begin{abstract}
Uma instituição total pode ser definida como um local de residência e trabalho onde um grande número de indivíduos com situação semelhante, separados da sociedade mais ampla por considerável período de tempo, levam uma vida fechada e formalmente administrada. As prisões servem como exemplo claro disso, desde que consideremos que o aspecto característico de prisões pode ser encontrado em instituições cujos participantes não se comportaram de forma ilegal. (GOFFMAN, 1974, P.11)
\end{abstract}

Mas ainda que o caráter de fechamento institucional e de sua separação do restante do corpo social seja comum aos dois autores, em Foucault a prisão apresenta um aspecto mais fortemente produtivo e disciplinar do que em Goffman, que enfatiza seu aspecto negativo. De qualquer modo, ambas as definições são úteis para pensarmos a prisão simulada apresentada em Detenção: seus integrantes não estão realmente inseridos no aparelho judiciário, são distribuidos espacialmente, classificados através de números, observados 24 horas por dia, mantidos nesse espaço por um período considerável de tempo, levam uma vida fechada, não possuem nenhum contato com o mundo exterior e tem sua vida administrada por terceiros, no caso os carcereiros.

Escolhemos esse filme como ilustração pelo fato de ele apresentar e manejar as relações de poder e os processos de resistência do início ao fim. Percebemos isso já na montagem de abertura do filme, onde são apresentadas imagens de ataques entre animais na natureza e, logo em seguida, conflitos entre seres humanos. Nessas imagens podemos ver a relação de poder de uns sobre os outros, questionando a intensificação das contradições e correlações de forças como, por exemplo, o uso excessivo de força policial durante uma manifestação social. No decorrer do filme percebemos também que não há apenas uma problematização das relações de poder

R. Inter. Interdisc. INTERthesis, Florianópolis, v.11, n.2, p.55-71, Jul./Dez. 2014
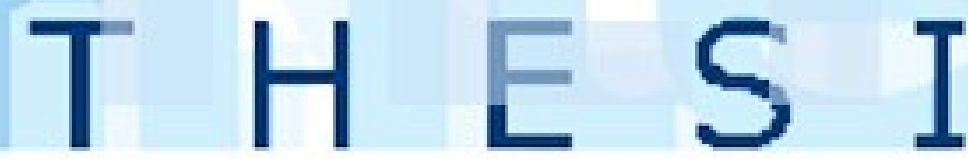
entre os dois grupos descritos acima, mas sim uma problematização de todas as relações apresentadas, sendo elas entre encarcerados e encarcerados, encarcerados e carcereiros e mesmo entre carcereiros e carcereiros.

Temos como principal interesse aqui discutir essas relações e tentar entender a partir de formulações teóricas, realizadas principalmente por Goffman e Foucault, o papel da instituição - aqui no caso a penal - na atribuição e na circulação de poder, a fim de refletirmos de que forma o poder é estabelecido e exercido dentro desses dois grupos.

As concepções teóricas acerca do poder variam dentro do espectro em que esse é analisado. Assim, podemos ver o poder ser habitualmente estudado nas ciências sociais através da óptica do Estado, da economia e, principalmente, das relações entre agentes sociais. Nesse paradigma, o poder é visto como a possibilidade efetiva de impor determinada ordem ou pensamento, mesmo que contra a vontade ou concordância do outro. Ainda nesse modelo o Estado assume o papel central no que concerne ao direito de exercer o poder, e a execução ou imposição deste ramifica-se por diversas nuances que engendram diferentes tipos de relações. Se, no entanto, pensarmos que para um poder ser exercido é necessária a sujeição do outro em obedecer, cabe nos perguntar: por que o outro obedece? Não obstante, se existe um poder que é exercido, quem o atribui àquele que o exerce?

Iremos perceber diferentes abordagens sobre o poder e diferentes formas pelas quais ele afeta os sujeitos, particularmente, os sujeitos inseridos em uma instituição penal. Temos, também, por objetivo em nosso trabalho entender de que forma o poder é exercido numa instituição através de uma memória que o transmite e o conserva. Por meio do filme Detenção podemos observar o modo pelo qual esse poder institucional acaba sendo exercido de forma distorcida.

As análises referentes ao poder em Foucault encontraram uma nova significação, distinta das que até então eram predominantes nas ciências sociais. $O$ autor afirma que não busca em suas análises enfatizar quem detém o poder, onde ele está localizado, ou de que maneira ele se constitui economicamente, ou seja, seu objetivo não é o de estudar o poder propriamente dito, mas sim o de pensar o sujeito e as consequências das complexas relações de poder que o afetam subjetivamente.

A partir da análise de Foucault entendemos o poder como algo inerente a todo o campo social; e, dialogando com o filme mencionado, entendemos que essas relações

R. Inter. Interdisc. INTERthesis, Florianópolis, v.11, n.2, p.55-71, Jul./Dez. 2014
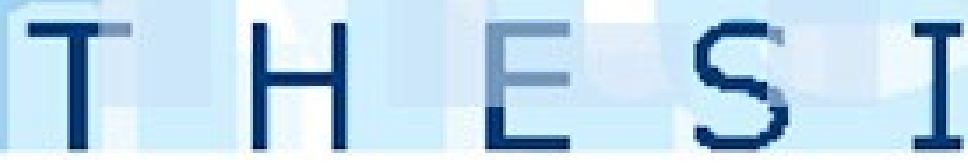
são, de fato, móveis. Isso explicaria a mudança de conduta dos sujeitos participantes do experimento, que ao migrar de determinada posição social para um a posição de carcereiros de uma instituição prisional fictícia, desempenham um papel repressor em nome do poder que lhes é atribuído, objetivando o controle sobre os corpos dos apenados através de mecanismos que visam torná-los dóceis. Em contrapartida, percebemos também a mudança comportamental dos encarcerados, buscando, como resistência, a afirmação dos valores disseminados entre seus iguais, ao mesmo tempo em que estão imersos numa instituição tida como disciplinar.

O artigo apresenta inicialmente as concepções de Instituição Total e Poder Binário em Goffman (1974) e a análise do filme com base nessas categorias teóricas e, posteriormente, discute as configurações e relações de poder a partir das obras de Foucault $(1987,2011)$, ressaltando as tensões, conflitos e formas de resistência exemplificadas no filme.

\section{INSTITUIÇÕES TOTAIS E PODER BINÁRIO EM GOFFMAN}

Em seus estudos sobre a instituição total, o sociólogo canadense Erving Goffman enfatiza o mundo dos internados e busca estudar a estrutura do eu a partir deste. Dentro das instituições totais, o autor postula que há uma divisão de grupos entre internados e dirigentes - que em nossa análise cinematográfica aparece como uma divisão entre encarcerados e carcereiros - afirmando também que as relações entre esses grupos se dão de maneira hostil, sendo limitadas por estereótipos por meio dos quais o segundo grupo visa à dominação e sujeição dos internados e o primeiro grupo se vê como dominado e sujeito aos dirigentes:

Nas instituições totais, existe uma divisão básica entre um grande grupo controlado, que podemos denominar o grupo dos internados, e uma pequena equipe de supervisão. Geralmente, os internados vivem na instituição e têm contato restrito com o mundo existente fora de suas paredes; a equipe dirigente muitas vezes trabalha num sistema de oito horas por dia e está integrada no mundo externo. Cada agrupamento tende a conceber o outro através de estereótipos limitados e hostis - a equipe dirigente muitas vezes vê os internados como amargos, reservados e não merecedores de confiança; os internados muitas vezes veem os dirigentes como condescendentes, arbitrários e mesquinhos. Os participantes da equipe dirigente tendem a sentirse superiores e corretos; os internados tendem, pelo menos sob alguns aspectos, a sentir-se inferiores, fracos censuráveis e culpados. (GOFFMAN, 1974, P.19)

R. Inter. Interdisc. INTERthesis, Florianópolis, v.11, n.2, p.55-71, Jul./Dez. 2014
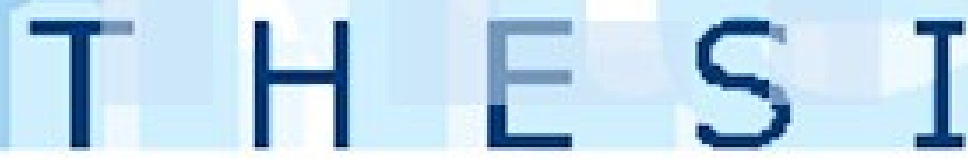
A relação binária entre os internados e os sujeitos, que ocupam uma posição hierárquica que permite o controle dos mesmos, se dá da seguinte maneira: a desobediência ou inadequação às normas é punida por privações (ficar sem almoço, sem colchão, não poder usar o banheiro etc.) e fisicamente (encarceramento em solitárias, sujeição dos corpos por agressões físicas, obrigação de exercícios extenuantes, sujeição sexual, entre outros). Dentro dessa relação também são previstos privilégios àqueles que se comportam e se adequam às normas, porém esses privilégios "não são iguais a prerrogativas, favores ou valores, mas apenas a ausência de provação que comumente a pessoa não espera sofrer" (Goffman, 1974. p. 52). Podemos perceber que essa relação binária não passa de uma relação de poder entre dominantes e dominados, ou melhor, entre dirigentes e internados.

Ao dar entrada em uma instituição total, o indivíduo é despido de sua aparência usual. Ele é identificado, numerado, fotografado, tiram suas impressões digitais, Ihes são atribuídas roupas da própria instituição, ou seja, um verdadeiro processo de despersonalização ocorre depois de sua admissão. Um indivíduo não é mais um indivíduo; ele passa a ser uma engrenagem no sistema da instituição, e a obedecer a todas as regras da mesma; caso não o faça, será "reeducado" pelos próprios companheiros ou pela equipe dirigente. É como se the tirassem as próprias memórias e as substituíssem por memórias da própria instituição que visam à padronização dos sujeitos.

Uma vez que o internado seja despojado de seus bens, o estabelecimento
precisa providenciar pelo menos algumas substituições, mas estas se
apresentam sob forma padronizada, uniformes no caráter e uniformemente
distribuídas. Tais bens substitutos são claramente marcados como
pertencentes à instituição e, em alguns casos são recolhidos em intervalos
regulares para, por assim dizer, serem desinfetados de identificações.
(GOFFMAN, 1974.P.28)

Esse processo que podemos entender, de acordo com Goffman, como "mortificação do eu" apresenta-se sob diversos aspectos que envolvem ou não a marca do corpo (mutilações, agressões físicas etc.). Embora haja relatos desse tipo de ação contra o corpo - no filme Detenção, por exemplo, a agressão física é levada ao extremo, chegando ao ponto de o grupo dos carcereiros urinar em cima de um detento indefeso, lembrando que os carcereiros urinaram no preso em função da impossibilidade de uso da violência física, ou seja, em função da proibição da violência física eles utilizaram a violência da humilhação - é mais frequente que as técnicas de mortificação do eu se deem através de mecanismos mais sutis, como os ritos de R. Inter. Interdisc. INTERthesis, Florianópolis, v.11, n.2, p.55-71, Jul./Dez. 2014
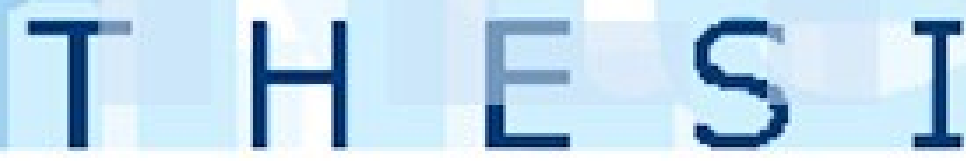
processo de admissão (banhos, desinfecções, cortes específicos de cabelo, distribuição de roupas e instruções a serem seguidas). No entanto, a forma mais contundente dessa mortificação se dá através de ações de infantilização do eu civil, onde o internado precisa de permissão para hábitos diários que antes faria sozinho, como permissão para ir ao banheiro, horários para comer, dormir e principalmente através da anulação de seu nome convertido para um número de identificação. $\mathrm{O}$ autor também afirma:

\begin{abstract}
Nas instituições totais há outra forma de mortificação; a partir da admissão, ocorre uma espécie de exposição contaminadora. No mundo externo, o indivíduo pode manter objetos que se ligam aos seus sentimentos do eu - por exemplo, seu corpo, suas ações imediatas, seus pensamentos e alguns dos seus bens - fora de contato com coisas estranhas e contaminadoras. No entanto, nas instituições totais esses territórios do eu são violados; a fronteira que $o$ indivíduo estabelece entre seu ser e o ambiente é invadida e as encarnações do seu eu são profanadas. (GOFFMAN, 1974. P.49)
\end{abstract}

Tais táticas que visam à mortificação do eu são apresentadas nitidamente no experimento científico que embasou o filme. Inicialmente o grupo de carcereiros sujeitos comuns que têm a tarefa de representar o poder institucional - recebeu a instrução de que poderia fazer o que quisesse desde que não usasse a agressão física. No entanto, o envolvimento com a experiência e a "detenção" do poder que Ihes foi atribuído fez com que esses tomassem atitudes que levaram a experiência a um ponto onde o controle foi perdido. Começou assim a agressão física e humilhação daqueles que receberam os papéis de internos, numa escala que variava desde a humilhação na hora em que era feita a contagem dos presos, até a privação de usarem banheiros ou dormirem em sua própria cela. Os presos, por sua vez, em um primeiro período, aceitaram esse papel de sujeição que começou desde sua inclusão no experimento. Eles passaram pelo rito de iniciação e, aos poucos, foram internalizando o papel de verdadeiros presos, sendo submetidos aos elementos de coerção aqui identificados.

Esses processos podem ser irreversíveis ou de reversibilidade difícil, dependendo do tempo em que um interno passe na instituição. As instituições totais são consideradas por Goffman instituições caracterizadas pelo seu fechamento, representando um híbrido social, constituído parcialmente enquanto grupo residencial e parcialmente como organização formal.

Assim, uma equipe dirigente pode ver um grupo de internados como um material passível de ajustes para seu pleno funcionamento, o que por sua vez

R. Inter. Interdisc. INTERthesis, Florianópolis, v.11, n.2, p.55-71, Jul./Dez. 2014
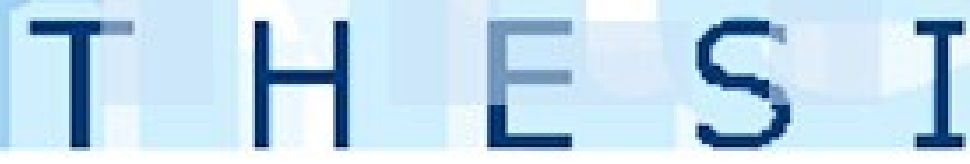
justificaria as sanções e coerções no cárcere. No entanto, se por um lado esse poder é exercido com uma conivência jurídica onde o status de dirigente permite o controle dos internados, por outro lado as relações entre os internos podem funcionar de forma a que as normas burladas não cheguem ao conhecimento dos dirigentes; de maneira análoga os próprios internos elegem quem os representa, tendo-o como uma espécie de líder, o que o Goffman chama de "ajustamentos secundários". No filme podemos ver nitidamente esse tipo de associação entre os presos, que, mesmo inicialmente aceitando as regras impostas pela instituição, acabaram por formar um grupo onde os ajustamentos secundários crescem a ponto de os internos se rebelarem, abortando a experiência.

Uma análise final proposta pelo autor, que, no entanto, não aparece no filme, é o fato de alguns internados ao receberem liberdade condicional preferirem manter-se presos. Num universo mais amplo de instituições totais de fato, a observação foi a de que muitas pessoas, após obterem sua liberdade tão esperada, acabam por não se adaptar à sociedade fora da instituição. Para alguns indivíduos, a aniquilação do seu eu teria sido tão forte que eles não conseguem mais se enquadrar na sociedade, nem mesmo saber qual papel devem representar daí por diante, sendo muitas vezes estigmatizados e, em alguns casos, preferem retornar à instituição onde viveram por um período de tempo com um papel especificamente definido.

\section{FOUCAULT E O PODER}

As prisões surgiram (Foucault, 1987) com a finalidade precípua de domesticar os corpos, fazê-los dóceis, principalmente para suportar jornadas árduas de trabalho. Em princípio, foram criadas as casas de correção, com a intenção de "regenerar" aqueles indivíduos considerados "vagabundos". Eram consideradas grandes fábricas onde o trabalho era atrelado à disciplina intensa, de forma a reeducar aqueles que lá estavam. Segundo Foucault (1987): "O essencial é procurar corrigir, reeducar, 'curar', uma técnica de aperfeiçoamento recalca, na pena, a estrita expiação do mal e liberta os magistrados do vil ofício de castigadores." (FOUCAULT, 1987, p. 13).

Para Foucault (1987) a horribilidade do mal cometido pelo acusado deveria ser representada no seu próprio corpo e da reparação do próprio mal causado. Essa representação também era entendida como uma forma de reafirmar a autoridade e o

R. Inter. Interdisc. INTERthesis, Florianópolis, v.11, n.2, p.55-71, Jul./Dez. 2014
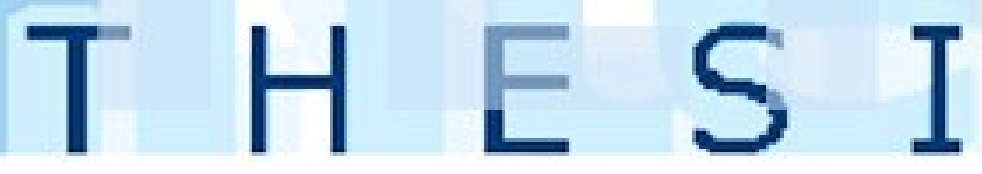
poder do Soberano; seu caráter público serviria de exemplo a todos, e assim, possuía função de prevenção da criminalidade.

Num segundo momento, a aplicabilidade da pena ao acusado foi sendo reformulada. O suplício dos corpos passou a receber críticas intensas por juristas e teóricos do direito, sobretudo a partir da violência que era empregada neste exemplo de exercício legítimo do poder real; a partir daí é reclamada a justiça, a punição ao invés da vingança. (Foucault, 1987).

Além da mudança do caráter punitivo, os crimes também se redimensionam, deixando a ênfase na dimensão de extrema violência e passando a se relacionar a gênese e intensificação das expressões da Questão Social. Neste contexto, torna-se emergente a mudança na Lei, no sentido de garantir proteção à propriedade privada. Toda esta reformulação faz parte de uma lógica denominada por Foucault (1987) de "economia do poder".

O verdadeiro objetivo da reforma, e isso desde suas formulações mais gerais, não é tanto fundar um novo direito de punir a partir de princípios mais equitativos; mas estabelecer uma nova "economia" do poder de castigar, assegurar uma melhor distribuição dele, fazer com que não fique concentrado demais em alguns pontos privilegiados, nem partilhado demais entre instâncias que se opõem; que seja repartido em circuitos homogêneos que possam ser exercidos em toda a parte, de maneira contínua e até o mais fino grão do corpo social. (FOUCAULT, 1987, p. 101).

O criminoso agora não é caracterizado mais como um inimigo do soberano, mas como um inimigo público, um "inimigo do corpo social", consequentemente, o direito de punir deixa de se relacionar à vingança e passa a ser considerado uma ação de defesa da sociedade.

A punição continua servindo ao caráter de prevenção em relação aos novos crimes, e neste sentido:

(...) os reformadores pensam dar ao poder de punir um instrumento econômico, eficaz, generalizável por todo o corpo social, que possa codificar todos os comportamentos e consequentemente reduzir todo o domínio difuso das ilegalidades. (FOUCAULT, 1987, p. 114).

O corpo do condenado deixa de ser considerado uma propriedade do soberano e passa a constituir-se em um bem social, passível de apropriação coletiva e útil.

A pena de prisão, segundo Foucault (1987), passa a figurar, como casas de correção, com trabalho obrigatório nas oficinas, e com as despesas na prisão custeadas por esse trabalho.

A vida é então repartida de acordo com um horário absolutamente estrito, sob uma vigilância ininterrupta: cada instante do dia é destinado a alguma coisa,

R. Inter. Interdisc. INTERthesis, Florianópolis, v.11, n.2, p.55-71, Jul./Dez. 2014
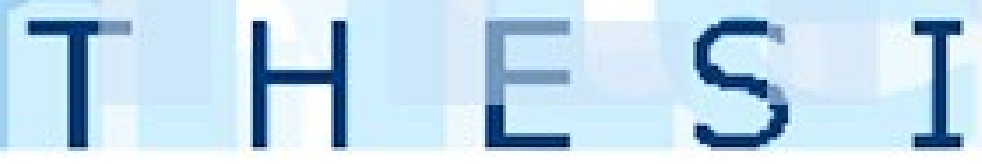
prescreve-se um tipo de atividade e implica obrigações e proibições. (FOUCAULT, 1987, p. 143).

O que se busca, como dito anteriormente, é fabricar um corpo dócil, apto e produtivo, nos moldes da sociedade capitalista. Pode-se afirmar que:

E finalmente, o que se procura reconstruir nessa técnica de correção não é tanto o sujeito de direito, que se encontra preso nos interesses fundamentais do pacto social: é o sujeito obediente, o indivíduo sujeito a hábitos, regras, ordens, uma autoridade que se exerce continuamente sobre ele e em torno dele, e que ele deve deixar funcionar automaticamente nele. (FOUCAULT, 1987, p. 148).

A instituição prisão, portanto, criada entre os séculos XVII e XVIII, constituiu-se como um dos mais eficientes mecanismos de controle social e coerção. Advinda de um período histórico específico, compreendido entre o Feudalismo e a transição para o modo de produção capitalista. O germe da aparelhagem prisional já existia, uma vez que havia neste período esforços para treinar os corpos, tornando-os úteis e produtivos para o trabalho. Todavia, é somente no século XIX que a instituição prisão melhor é delineada, dotando-a com a penalidade de detenção.

As prisões, consequentemente, funcionam seguindo a "lógica da disciplina", o que significa dizer que pertencem a uma engendrada estrutura que é exercida seguindo uma "codificação que esquadrinha ao máximo o tempo, o espaço, os movimentos", através do "controle minucioso das operações do corpo", buscando impô-lo "uma relação de docilidade-utilidade". (Foucault, 1987: 164). O corpo do condenado passa a ser um bem público, seu crime passa a ser visto como uma conduta antissocial e, portanto, o criminoso é um inimigo do povo. Como punição, o indivíduo é isolado socialmente. O castigo passa a ser a diretriz que move a pena de detenção, é preciso punir não somente o corpo, mas a alma também. De acordo com Michel Foucault (1987):

\footnotetext{
Mas a obviedade da prisão se fundamenta também em seu papel, suposto ou exigido, de aparelho de transformar os indivíduos. Como não seria a prisão imediatamente aceita, pois se só o que ela faz, ao encarcerar, ao retreinar, ao tornar dócil, é reproduzir, podendo sempre acentuá-los um pouco, todos os mecanismos que encontramos no corpo social (p. 6).
}

Aos poucos, o corpo passa a "obedecer" aos sinais e regras que lhe são impostos. $\mathrm{Na}$ sociedade, disciplinar a subjetividade pode ser produzida como identidade, sendo a própria identidade uma produção do poder. O poder e suas instituições produzem identidade e individualidade, não sendo o poder restritivo, mas produtivo.

R. Inter. Interdisc. INTERthesis, Florianópolis, v.11, n.2, p.55-71, Jul./Dez. 2014
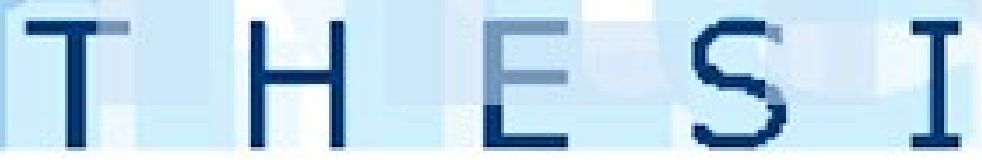
O poder disciplinar constrói uma sociedade disciplinar, adestrando, produzindo coletivamente corpos individualizados e dóceis. Trata-se de uma modalidade de poder produtivo, e não essencialmente restritivo, mutilador ou repressivo, que liga as forças para multiplicá-las e utilizá-las em sua totalidade, apropriando-se delas ainda mais e melhor. A ação do poder disciplinar é essencialmente produção de subjetividade moderna.

Foucault não tem o poder como uma unidade estável e nem como uma entidade dividida em duas partes: dominantes e dominados. Ele recusa a centralização do poder localizada no Estado, para ele esse tema é um tanto mais complexo.

O poder nunca se encontra total, inteiramente, num dos lados. Não há algo como, de um lado, os que "detém" o poder e, do outro, os que dele são inteiramente privados. A relação com o poder não está contida num esquema de passividade. (FOUCAULT, 1979, P.47)

Mas ainda que o tema poder pareça ser o centro de seus estudos, como já foi dito inicialmente, sua grande questão é o sujeito. "Não é, portanto, o poder, mas o sujeito que constitui o tema geral de minha pesquisa" (FOUCAULT, 1995, p.232). Recusando a centralização deste, ele o mostra com uma nova problematização e o enxerga como forma secundária em suas análises. Como Foucault nunca dedicou um livro à sua definição de poder existem muitas interpretações equivocadas ou mal entendidas sobre $o$ assunto.

Caracterizando as relações de poder como modos de ação complexos sobre a ação dos outros, o autor não acredita que uma instituição possa ser detentora de um poder absoluto, mas sim um lugar que intensifica as relações de poder, sejam essas entre indivíduos e classes, indivíduos e instituições ou, como priorizamos aqui, encarcerados e carcereiros. "A cada instante, o poder participa de um jogo composto de pequenas partidas singulares" (FOUCAULT, 1979, p.47), ou seja, ele nunca é controlado por um grupo determinado. O que acaba, portanto, com a ideia de contradição entre poder e liberdade, o poder não se exerce somente quando o sujeito perde sua liberdade, pelo contrario:

Quando definimos o exercício do poder como um modo de ação sobre as ações dos outros, quando as caracterizamos pelo "governo" dos homens, uns pelos outros - no sentido mais extenso da palavra, incluímos um elemento importante: a liberdade. O poder só se exerce sobre "sujeitos livres", enquanto "livres" - entendendo-se por isso sujeitos individuais ou coletivos que têm diante de si um campo de possibilidade onde diversas condutas, diversas reações e diversos modos de comportamento podem acontecer. Não há relação de poder onde as determinações estão saturadas - a escravidão não é uma relação de poder, pois o homem está acorrentado (trata-se então de

R. Inter. Interdisc. INTERthesis, Florianópolis, v.11, n.2, p.55-71, Jul./Dez. 2014
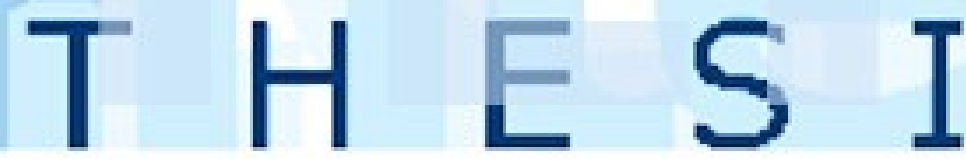
uma relação física de coação) - mas apenas quando ele pode se deslocar e, no limite, escapar. Não há, portanto, um confronto entre poder e liberdade, numa relação de exclusão (onde o poder se exerce, a liberdade desaparece); mas um jogo muito mais complexo: neste jogo, a liberdade aparecerá como condição de existência do poder (ao mesmo tempo sua precondição, uma vez que é necessário que haja liberdade para que o poder se exerça, e também seu suporte permanente, uma vez que se ela se abstraísse inteiramente do poder que sobre ela se exerce, por isso mesmo desapareceria, e deveria buscar um substituto na coerção pura e simples da violência); porém, ela aparece também como aquilo que só poderá se opor a um exercício de poder que tende, enfim, a determiná-la inteiramente. (FOUCAULT, 1995, P.244)

No filme, os cárceres tiveram a opção de desistir da experiência assim que um deles sofreu a primeira agressão física, mas, visando o dinheiro, foram aceitando a situação de submetidos à relação de poder dos carcereiros até um deles ser morto.

Essa complexidade das relações vista em Foucault é o principal ponto de afastamento do pensamento sobre poder em Goffman. Aqui não mais entenderemos o poder sob a forma binária anteriormente apresentada, na qual dirigentes detinham o poder institucional e internados eram submetidos inteiramente a eles. Aqui o poder se encontra em todos os lados, em todas as relações:

Ele chega a se exercer ou não, ou seja, o poder consiste sempre numa
determinada forma de embates instantâneos e continuamente renovados entre
determinado numero de indivíduos. Não se detém o poder, pois se joga com,
arrisca-se o poder. Como numa batalha, ganha-se ou perde-se o poder. No
cerne do poder, há uma relação bélica e não uma relação de apropriação.
(FOUCAULT, 1979, P.47)

Podemos exemplificar o que foi dito através do filme Detenção. Nele, o carcereiro principal (interpretado por Forest Whitaker, ator que protagonizou $O$ Último Rei da Escócia) acredita que pode se apropriar do poder institucional para exercer uma autoridade para com os presos de uma forma distorcida das regras que thes foram passadas. Ao perceber que os cientistas por trás das câmeras da falsa prisão não encerram o experimento mesmo após ser usada agressão física, o carcereiro principal vai progressivamente e erroneamente acreditando que ele detém todo o poder e todos os outros residentes da instituição, inclusive seus companheiros carcereiros, estão submetidos a ele. Dessa forma, ele se enxerga como o centro do poder absoluto. Partindo dos escritos de Foucault sobre esse assunto, podemos imaginar que isso seria apenas uma ilusão de poder, mas jamais um poder tal como ele de fato é exercido. Como já foi dito, a relação de poder não é uma relação de apropriação e o filme corrobora essa perspectiva ao mostrar que não apenas os encarcerados, mas alguns carcereiros também se rebelam contra esse tipo de poder

R. Inter. Interdisc. INTERthesis, Florianópolis, v.11, n.2, p.55-71, Jul./Dez. 2014
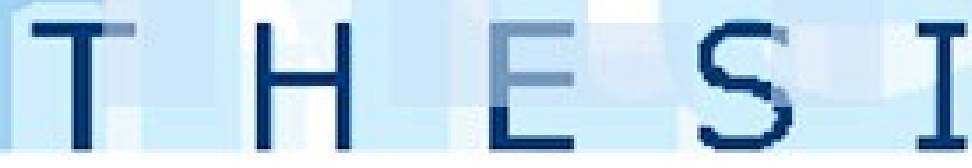
centralizador. Por mais que a prisão seja uma instituição disciplinar, visto que suas principais características são o controle dos corpos e uma vigilância permanente, jamais podemos supor que de um lado se encontra o poder e do outro "aquilo sobre o qual ele se exerceria" (FOULCAULT, 2012, P.271). O poder está em todos os lados, em todas as classes e em todos os conflitos sociais, sendo cada instituição perpassada por instâncias, relações e jogos de poder, mas também por processos de resistência e luta pela reconfiguração do poder.

\section{CONSIDERAÇÕES FINAIS}

Goffman ao estudar as instituições totais baseou-se na relação binária que se estabelece entre os internados e os dirigentes, em nosso exemplo vistos como aqueles que ocuparam no filme o papel de encarcerados e aqueles que encenaram $o$ papel de carcereiros. O autor postulou que essas relações se dão de forma que os dirigentes da instituição buscam a adequação dos internados, sobretudo através da mortificação do eu. Para que isso ocorra, recorrem a diversos mecanismos que visam essa anulação, por meio dos quais o internado perde sua identidade através de ações que o igualam aos demais detentos: são colocados em posição que vestem roupas iguais, herdadas de outros detentos, possuem o mesmo corte de cabelo, submetem-se às mesmas normas e, principalmente, são impedidos de exercerem direitos que Ihes eram atribuídos no mundo externo num viés onde passam a depender dos dirigentes para ações tidas como comuns: como tomar banho, utilizar banheiro, tomar sol e demais atividades que Ihes eram individuais.

O interno então passa a viver em um paradigma temporal onde não há rupturas, buscando ocupar o seu tempo com ações que lhe são impostas; o que não ocorre num mundo exterior à instituição. No mundo exterior ele pode escolher de que forma utiliza seu tempo, havendo rupturas para conversas, lanches, cafés, idas a um centro cultural, assistir televisão ou simplesmente conversar com os amigos. Essa estrutura que conjuga o controle de suas ações, de seu tempo, a perda do seu nome por um número, a condição de exercer as mesmas funções sociais dentro de um determinado grupo o levam a perda de sua percepção subjetiva, mortificando assim o seu eu.

Numa análise daqueles que constituem os dirigentes, Goffman entende que esses passam a representar o poder jurídico dentro das instituições, uma vez que lhes

R. Inter. Interdisc. INTERthesis, Florianópolis, v.11, n.2, p.55-71, Jul./Dez. 2014
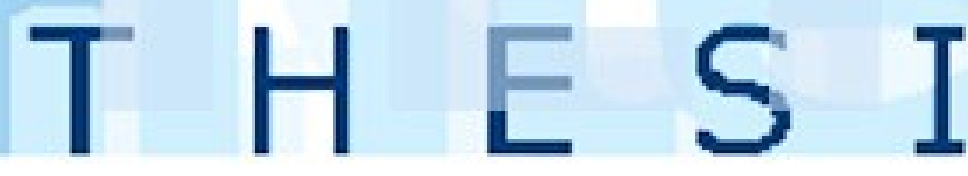
é atribuído o poder das decisões tanto administrativas quanto coercitivas, dessa forma a própria instituição tenderá a ser interpretada como propriedade da equipe dirigente. Aqui encontramos uma possível explicação para a forma pela qual pessoas comuns que se submeteram à experiência, ao assumirem o papel de dirigentes, internalizam esse poder e reproduziram ações que seriam tidas como comuns numa instituição total de fato. Cabe a nós perceber que mesmo fora de uma instituição total o sujeito toma conhecimento, mesmo que de maneira superficial, de determinadas regas da instituição, e mesmo que considerem essas regras arbitrárias tendem a reproduzi-las no momento em que fazem parte de um determinado grupo social. Isso nos abre a perspectiva de que as demais instituições reproduzem em maior ou menor grau esse paradigma, então para Goffman todas as instituições tendem a se fecharem. No entanto, o autor parece levar pouco em consideração que as relações não são estáticas, e sim fluidas, portanto, ocorrem oposições a tais sujeições. Nesse sentido a ideia de articulação entre os internados nos parece superficial o que, todavia, pode ser explicado pela época em que foi estudada. O próprio filme mostra de forma clara que embora num princípio haja sujeição por partes dos apenados, esses tendem a construir formas de resistência, organizando-se a partir de um grupo.

Relacionando os estudos de Goffman com o filme analisado, encontramos a correlação entre a pesquisa do autor e a produção do cineasta, até porque o filme parte da primeira; assim reforçamos a ideia de que mecanismos de poder são exercidos por aqueles a quem os tem concebido, tal fato, com já mencionado pode ter suas raízes em comportamentos sociais preestabelecidos e que de certa forma corroboram as normas das instituições, mesmo quando não fazemos parte dela.

A prisão como instituição total é organizada para proteger a sociedade contra perigos intencionais, tendo como foco principal a disciplina, a punição e manutenção da segurança, sendo caracterizada por uma rotina institucionalizada e massificada, muitas vezes, considerada e definida como um local de residência e trabalho.

Esse espaço físico fechado representa para os presos a tranca, a massificação de comportamentos e uma adaptação de seus hábitos e costumes, disciplinando horários e institucionalizando uma rotina.

Conforme propõe Foucault (1987), devemos compreender as relações de luta e de poder; assim entenderemos as leis, as relações sociais e as construções arquitetônicas, onde se encontram explícitas as relações de poder e de domínio. A

R. Inter. Interdisc. INTERthesis, Florianópolis, v.11, n.2, p.55-71, Jul./Dez. 2014
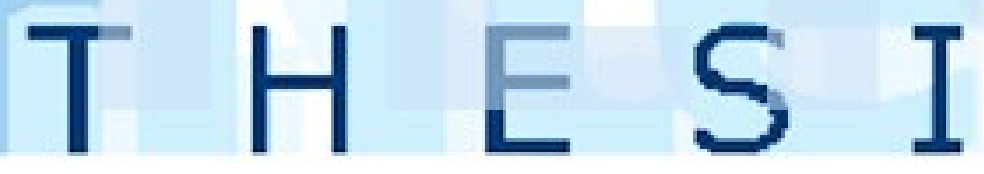
disciplina é utilizada nas diversas instituições sociais - como as fábricas, escolas e, principalmente, nas prisões - como forma de coerção para a produção de sujeitos dóceis e úteis, ou seja, a força de trabalho precisa ser controlada em benefício do capital. O poder disciplinar utiliza instrumentos como o olhar de vigilância e hierarquia, a sanção normalizadora e a combinação do sistema duplo de gratificação e sanção.

Este processo também é apresentado por Augusto Thompson (2002), em sua famosa obra "A questão penitenciária", que fala do fenômeno "prisionização", constituindo um processo de socialização diferente dos padrões e valores sociais considerados "normais". Ou seja, a "prisionização" configura-se pela incorporação pelos indivíduos dos comportamentos e modos de sociabilidade inerentes à prisão, sendo considerada inaceitável dentro dos padrões sociais dos indivíduos em sociedade livre.

R. Inter. Interdisc. INTERthesis, Florianópolis, v.11, n.2, p.55-71, Jul./Dez. 2014 


\title{
DETENTION: THE RELATIONSHIP OF POWER BETWEEN PRISONERS AND JAILERS FROM THE STUDIES OF GOFFMAN AND FOUCAULT
}

\begin{abstract}
:
The aim of this article is to discuss the relations of power between prisoners and jailers, inside prison institutes from the movie The Experiment, 2010, directed by Paul Scheuring. We start from the concept of "total institution" and "prison-form" established by Erving Goffman and Michel Foucault, respectively, in order to reflect how the power is established and exercised between and inside these two groups (prisoners and jailers). Based on the movie, we try to observe the consequences of the power given by the institution to the jailers, here as a leading team, and how this same power acts on the prisoners, leading them gradually to a change in subjectivity and consequent annulation of the civil-self.
\end{abstract}

Keywords: Institution. Power. Prison. Cinema.

\section{DETENCIÓN: LA RELACIÓN DE PODER ENTRE PRESOS Y CARCELEROS A PARTIR DE LOS ESTUDIOS DE GOFFMAN Y FOUCAULT}

\section{Resumen:}

El objetivo de este artículo es discutir las relaciones de poder entre los presos y carceleros, dentro de las instituciones penales a partir de la película El Experimento de 2010, dirigida por Paul Scheuring. Partimos de los conceptos de "institución total" y "forma-prisión" establecidos por Erving Goffman y Michel Foucault, respectivamente, con el fin de reflejar cómo el poder es establecido y ejercido entre y dentro de estos dos grupos (prisioneros y carceleros). A partir de la película tratamos de observar las consecuencias del poder cedido por la institución a los carceleros, considerados aquí como un equipo dirigente, y cómo este mismo poder actúa sobre los presos, llevándolo progresivamente a una modificación de la subjetividad en cuanto anulación del yo civil.

Palabras clave: Institución. Poder. Prisión. Cine.

R. Inter. Interdisc. INTERthesis, Florianópolis, v.11, n.2, p.55-71, Jul./Dez. 2014
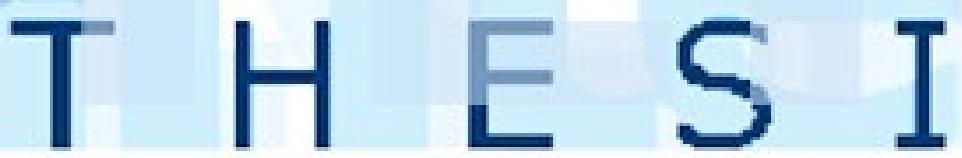


\section{REFERÊNCIAS}

GOFFMAN, Erving. Manicômios, prisões e conventos. São Paulo: Perspectiva, 1974.

FOUCAULT, Michel. Ditos e Escritos Volume IV: estratégia, poder-saber. RJ: Forense Universitária, 2012.

. Vigiar e Punir. 39ª ed. Petrópolis, RJ: Vozes, 1987.

. Vigiar e Punir. 39ª ed. Petrópolis, RJ: Vozes, 2011.

O Sujeito e o Poder. In. RABINOW, Paul e DREYFUS, Hubert

(Org). Michel Foucault. Uma trajetória filosófica. Para além do estruturalismo e da hermenêutica. RJ: Forense Universitária, 1995.

O Poder e a Norma. In. KATZ, Chaim Samuel (Org). Psicanálise

Poder e Desejo. IBRAPSI, 1979.

THOMPSON, Augusto. A questão penitenciária. 5ª Ed. Rio de Janeiro: Forense, 2002.

\section{FILMOGRAFIA:}

Detenção (The Experiment)

Direção: Paul Scheuring

Roteiro: Paul Scheuring e Mario Giordano (novela)

Ano da produção: 2010

Elenco principal: Adrien Brody, Forest Whitaker e Cam Gigandet. 